\title{
A BETA TEST COMPARISON BETWEEN THE NEW PACKARD 2260 XL AND THE LKB QUANTULUS AND 1219 SM: LOW-LEVEL RADIOCARBON AND TRITIUM DETERMINATIONS
}

\author{
ROBERT M KALIN \\ Laboratory of Isotope Geochemistry, Department of Geosciences \\ University of Arizona, Tucson, Arizona 85721
}

\begin{abstract}
A Packard 2260 XL liquid scintillation counter was placed in an underground counting chamber to test performance under immense physical shielding. Results from the Packard $2260 \mathrm{XL}$ are compared with two other counters under the same conditions, the LKB Quantulus, which has operated for two years in this laboratory, and the LKB 1219 SM, in use since January 1988.
\end{abstract}

\section{INTRODUCTION}

The University of Arizona received a new Packard Instrument $2260 \mathrm{XL}$ liquid scintillation (LS) counter for evaluation during the spring of 1988. The Packard Instruments Company was interested in determining the performance of this counter under immense physical shielding and strict climate control (constant temperature of $15^{\circ} \mathrm{C}$ and two dehumidifiers) found in our underground counting chamber. We were also asked for our independent evaluation of the application of the $2260 \mathrm{XL}$ to ${ }^{14} \mathrm{C}$ dating and tritium measurements. This counter uses a novel approach to background reduction (Noakes \& Valenta, 1989) which is a step in a new direction for LS counting. A plastic insert and electronic circuitry allow the photo tubes to select between background and real sample events.

The objectives of this study were to determine the laboratory and counting procedures and techniques best suited for ${ }^{14} \mathrm{C}$ dating with the Packard $2260 \mathrm{XL}$, to test the feasibility of counting natural levels of tritium using the Packard $2260 \mathrm{XL}$, and to compare these results with the results of similar tests using the LKB Quantulus and the LKB 1219 SM.

\section{VIAL SELECTION}

For ${ }^{14} \mathrm{C}$ dating, our laboratory uses $20 \mathrm{ml}$ low-potassium glass vials that are masked for all but the bottom $1.3 \mathrm{~cm}$ (Fig 1). Into these vials we syringe $3.0 \mathrm{ml}$ of benzene. The vial is weighed, sealed with a teflon cap liner and the activity of the sample is measured. The Packard Instrument Company supplied $7 \mathrm{ml}$ low-potassium glass vials and special plastic vial holders for evaluation with the 2260XL (Fig 1). There is no need for special masking when using the plastic vial holders. Both vials are acceptable. The energy spectrum of samples counted using the $20 \mathrm{ml}$ masked vials is somewhat compressed at the high-energy end when compared to the $7 \mathrm{ml}$ vials in the special vial holders. This is most likely due to the sample alignment, the $7 \mathrm{ml}$ vials will hold more of the sample closer to the center plane of the phototubes. These vials can also be sealed with commercially available teflon cap liners, 

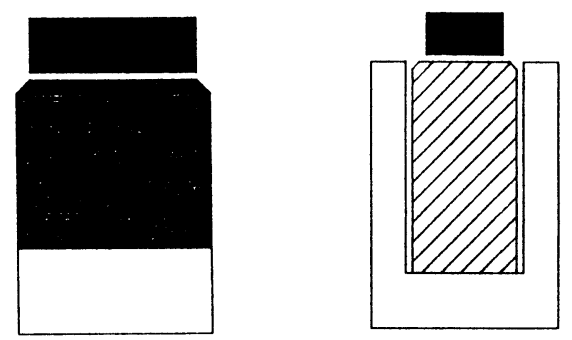

Fig 1. A $20 \mathrm{ml}$ masked low-potassium vial and a $7 \mathrm{ml}$ low-potassium glass vial in a special plastic vial holder

and showed no evaporation during the extent of this study. The data presented for the Packard $2260 \mathrm{XL}$ was collected using the $7 \mathrm{ml}$ vials.

\section{RESULTS AND DISCUSSION}

I used butyl-PDB as the scintillant for the first ${ }^{14} \mathrm{C}$ samples in the Packard 2260XL counter. Past experiments with the Quantulus and Packard $460 \mathrm{C}$ counters have shown that $0.95 \mathrm{wt} \%$ butyl-PBD added to the sample benzene is desirable due to the high efficiency of photon yield and because it does not add to sample volume. The counting efficiency of samples in the $2260 \mathrm{XL}$ which have $0.95 \mathrm{wt} \%$ butyl-PDB as the sole scintillant is $1.5 \%$. The special plastic absorbs light from the wavelength of the emission of butylPBD, $365 \mathrm{~mm}$, thereby turning on the quard and shutting down the counter to detect valid pulses (Noakes, pers commun, June 1988). Experiments in which a second scintillant was added to the benzene-butyl-PDB mixtures were undertaken in the hope that the emission spectrum could be shifted above the absorption peak of the plastic. A second scintillant was added to the base cocktail so that samples could be routinely prepared for any counter we use and only those samples which were to be counted in the Packard $2260 \mathrm{XL}$ would have the second scintillant added.

Di-methyl POPOP was chosen for study because this scintillant has the highest wavelength emission of the solid scintillants available to us. Dimethyl POPOP is rather insoluble in benzene, and so, various amounts of this scintillant were added to background cocktails to determine in what weight percent this scintillant is soluble in our cocktail. I found that adding $0.20 \mathrm{wt} \%$ of di-methyl POPOP to $3 \mathrm{ml}$ of benzene with $0.95 \mathrm{wt} \%$ of butylPBD shifted the emission wave length of the solution without a loss of counting efficiency. No other secondary scintillant was tested. The spectrum and count rates of Oxalic Acid I (OXI) samples counted with di-methyl POPOP in our Packard 2250 LL counter were comparable to the samples of OXI continually counted in the $2250 \mathrm{LL}$ which have only butyl-PDB as the scintillant.

Figure 2 shows the spectrum of an OXI and a background benzene sample. These samples are fully oxygen quenched by allowing the samples to be in contact with atmosphere while sealed in a storage vial, and also 

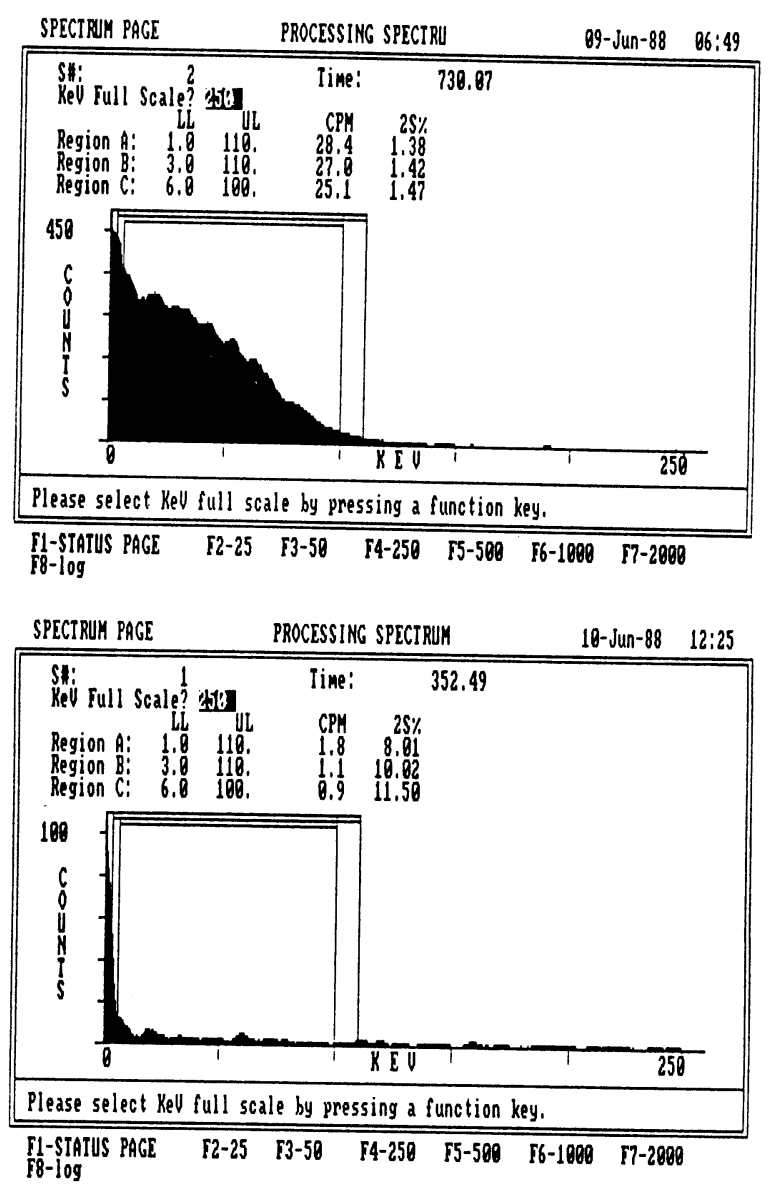

Fig 2. Energy spectrum of Oxalic Acid I and background samples in the Packard 2260 XL liquid scintillation counter

when placed in the counting vial. This completely saturates the benzene with atmospheric levels of oxygen.

Figure 3 shows individual 20-min intervals of an OXI and background benzene counted for one month in the Packard 2260 XL. It was hoped that $10,000 \mathrm{~min}$ of 50-min intervals could be collected for direct comparison with the data in Kalin and Long (1989), but due to time constraints, this was not possible. The optimized windows for this data were chosen using the same criterion as when setting the windows of our other counters. The window used for data collection was selected to maximize the figure of merit, while keeping the window limits in a portion of the spectrum which is changing rapidly. Two additional windows were set. These windows have the same upper energy limit but different low energy channels, the ratios of which help to detect any slight change in the energy spectrum. 


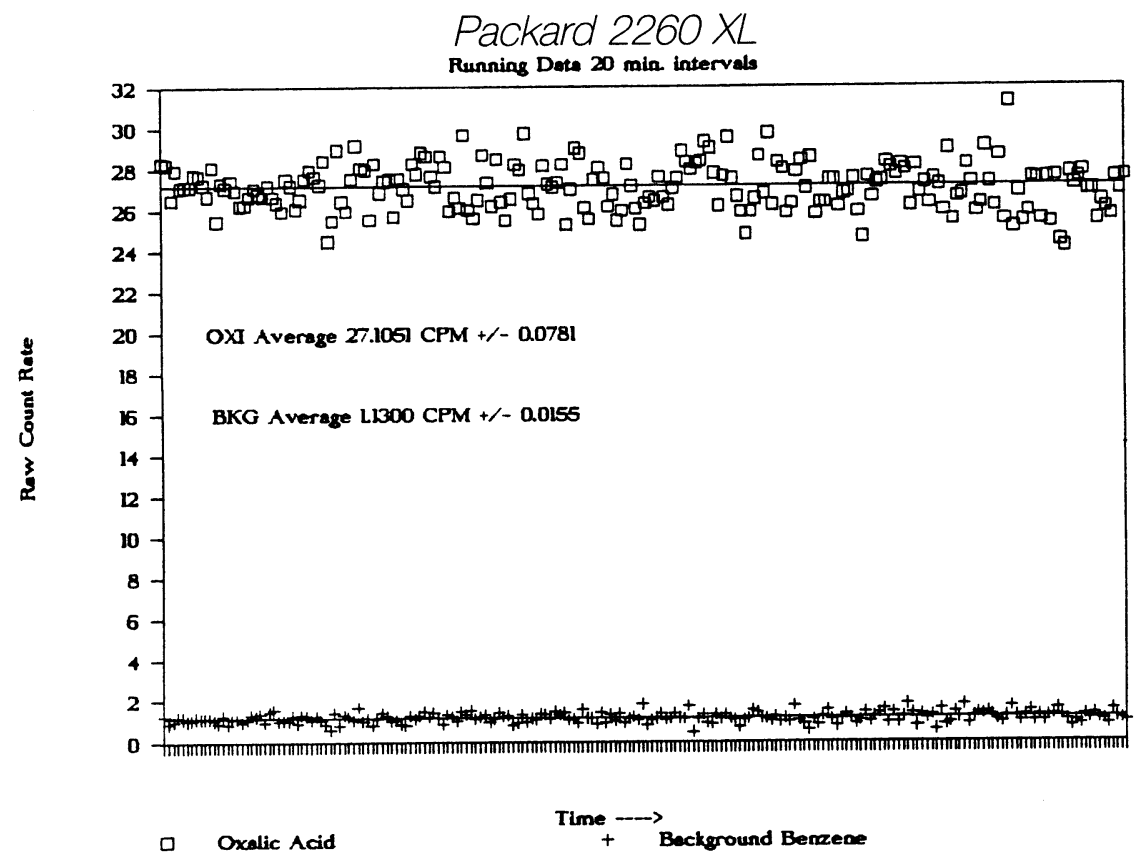

Fig 3. Series of standard and background 20-min intervals from the Packard 2260 XL.

Table 1 shows the results of the comparison between the Packard 2260 XL, LKB Quantulus, and the LKB 1219 SM counters using quenched background and quenched $\mathrm{OXI}{ }^{14} \mathrm{C}$ samples. Of the three counters the

\section{TABLE 1}

Performance characteristics of the Packard $2260 \mathrm{XL}$, LKB Quantulus and LKB 1219 SM for ${ }^{14} \mathrm{C}$ dating

\begin{tabular}{lccccc}
\hline \multicolumn{1}{c}{ Counter } & Efficiency* & Background* & E $/ \mathrm{B}$ & $\begin{array}{c}\text { Modern sample } \\
\text { Error (\%) }\end{array}$ & Max age \\
\hline $\begin{array}{l}\text { Packard 2260 XL } \\
\text { 7ml vials }\end{array}$ & 67.82 & 0.8136 & 5653 & 7 & 49,800 \\
$\begin{array}{l}\text { Packard 2260 XL } \\
\text { 20ml vials }\end{array}$ & 69.66 & 1.0273 & 4724 & - & - \\
LKB Quantulus & 67.73 & 0.3708 & 11762 & 4 & 53,400 \\
LKB 1219 SM & $65.99^{* *}$ & $3.27^{* *}$ & 1332 & $9^{\dagger}$ & $40,000^{\dagger}$ \\
\hline
\end{tabular}

${ }^{*}$ For window with the highest figure of merit

**The LKB 1219 SM counter has been optimized for figure of merit but this counter will not be used for ${ }^{14} \mathrm{C}$ dating.

${ }^{\dagger}$ These figures are calculated assuming the data follow a normal statistical distribution. 
Quantulus shows the most outstanding performance characteristics for ${ }^{14} \mathrm{C}$ dating, but the Packard $2260 \mathrm{XL}$ counter is approaching the performance of the Quantulus. The background count rate in the $2260 \mathrm{XL}$ is 2.19 times higher than the LKB Quantulus; the background count rate in the $2260 \mathrm{XL}$ is 4.02 times less than the LKB $1219 \mathrm{SM}$. The data collected from the Quantulus and the 1219 SM were on samples with butyl-PBD as the scintillant. The samples in the Packard counter used additional di-methyl POPOP as mentioned before. The new Packard 2260 XL counter is able to count a modern sample to at least $\pm 7 \%$ with 2000 min of counting, and has a maximum determinable age of 49,800 $\mathrm{yr}$ in our underground lab. These values are approaching the background, error of modern sample and maximum determinable age which our lab now obtains with our Quantulus LS counter. The LKB 1219 SM data (Table 1) are calculated based on the best operating parameters I have been able to achieve with this counter, and on the assumption that the count rate will follow normal statistics.

In addition to ${ }^{14} \mathrm{C}$ dating, our laboratory is beginning natural-level tritium determinations. Table 2 lists the background count rate, efficiency of counting and figure of merit for each counter for tritium. These data were collected by counting samples of deionized water from the Tucson Aquifer

TABLE 2

Performance of the Packard 2260 XL, LKB Quantulus and 1219 SM for measurement of tritium

\begin{tabular}{lccc}
\hline Counter & Efficiency & Background & Figure of merit $\left(\mathrm{E}^{2} / \mathrm{B}\right)$ \\
\hline $\begin{array}{l}\text { Packard 2260 XL } \\
\text { 20ml glass vials }\end{array}$ & 21 & 2.4 & 184 \\
Quantulus & 24 & 7.1 & 81 \\
20ml glass vials* & 24 & 13.8 & 43 \\
$\begin{array}{l}1219 \text { SM } \\
20 \mathrm{ml} \text { glass vials }\end{array}$ & & & \\
\hline
\end{tabular}

*Figure of merit increases dramatically if teflon or polyethylene vials are used in the Quantulus.

as the background sample, and an NBS tritium standard; $9 \mathrm{ml}$ of water were added to $9 \mathrm{ml}$ of Pico Flour LLT cocktail and mixed. These samples were counted in $20 \mathrm{ml}$ glass vials, chosen over polyethlyene vials to circumvent the diffusion of the cocktail through the vial so that the identical samples could be counted over time in each counter. The counting windows were chosen to maximize efficiency in each counter. These parameters are not optimized and further testing is needed to determine the optimal vial type, cocktail and energy windows for each counter. The efficiency of counting tritium is lower in the $2260 \mathrm{XL}$ than in both the LKB Quantulus and 1219 SM, but the 
background is a factor of ca 3 lower in the $2260 \mathrm{XL}$ than in the Quantulus and ca 5.8 lower than the $1219 \mathrm{SM}$. It should be noted that the background is elevated when measuring for natural tritium using glass vials in the Quantulus LS counter as compared to the same cocktails used in the special LKB teflon vials or with polyethylene vials (Kaihola, pers commun, June 1988). Schönhofer and Henrich (1987) report figure of merit values as high as 1849 for tritium samples counted in the Quantulus using teflon vials. These special teflon vials must be meticulously cleaned to ensure sample integrity. Other studies (Bowman, 1989; Kalin \& Long, 1989; Devine \& Haas, 1987) suggest that for routine counting, the use of teflon vials may not be desirable. The performance of the teflon or polyethylene vials in the LKB Quantulus, LKB 1219 SM or Packard 2260 XL was not tested.

\section{CONCLUSION}

This novel approach to LS counting circuitry found in the Packard 2260 $\mathrm{XL}$ yields performance characteristics suitable for ${ }^{14} \mathrm{C}$ dating. The measurement of natural levels of tritium is feasible with this LS counter but more work needs to be completed on parameter optimization. The comparison of the Packard 2260 XL, LKB Quantulus and 2219 SM has shown that, for ${ }^{14} \mathrm{C}$ dating, the $2260 \mathrm{XL}$ performance is approaching the Quantulus, and that the 1219 SM is lower than both the 2260 XL and the Quantulus. The results of tritium measurements using glass vials has shown that the $2260 \mathrm{XL}$ has better performance, but others report that when using teflon vials, the performance of the Quantulus is above the Packard 2260 XL.

\section{ACKNOWLEDGMENTS}

I would like to acknowledge the Packard Instrument Company for supplying the $2260 \mathrm{XL}$ counter for three months of testing, and for help in obtaining various solid scintillants for experimentation. I would also like to acknowledge the University of Arizona, Laboratory of Isotope Geochemistry, for support of this project.

\section{REFERENCES}

Bowman, S, 1989, Liquid scintillation counting in the London Underground: Radiocarbon, this issue.

Devine, J M and Haas, H, 1987, Scintillation counter performance at the SMU radiocarbon laboratory: Radiocarbon, v 29 , no. 1, p 12-17.

Kalin, R M and Long, A, 1989, Radiocarbon dating with the Quantulus in an underground counting laboratory: Performance and background sources: Radiocarbon, this issue.

Noakes, J and Valenta, R, 1989, Low background liquid scintillation counting using an active sample vial holder and pulse discrimination electronics: Radiocarbon, this issue.

Schönhofer, F and Henrich, E, 1987, Recent progress application of low level liquid scintillation counting: Jour Radioanal Nuclear Chem, v 115, no. 2, p 317-333. 